\title{
AS CRIANÇAS E A NATUREZA EM CONTEXTOS RURAIS AMAZÔNICOS
}

\author{
Eliana Campos Pojo Toutonge 1 \\ Maria Natalina Mendes Freitas 2
}

\section{RESUMO}

O artigo trata do convívio das crianças com a natureza amazônica em contextos rurais amazônicos da cidade de Abaetetuba-PA, sustentado pela ideia de que elas são seres relacionais e que se constituem em conexão com outros seres e que potencializam atividades e ações neste estado de conexão. Trata-se de uma investigação desenvolvida em 2018 e 2019, que abarcou pesquisas bibliográfica e de campo, utilizando-se recursos etnográficos, cuja centralidade foram entrevistas e observações com as crianças, levando em consideração suas vozes e suas opiniões, tomando-as como sujeitos sociais, produtoras de conhecimento e de uma sociabilidade com seus pares e com adultos. Como resultado, foi possível perceber que as crianças desses contextos possuem concretamente uma conexão com o solo natural, por meio de vivências junto da mãe terra e das águas, ou seja, há uma atitude prospectiva de reinvenção dos conteúdos culturais existentes no lugar através de seus brincares e de outras experiências e, ao mesmo tempo, seus valores do conviver, suas tradições ricas de simbologias amazônicas convertem-se em processos educativos no ordinário da vida. Estes indícios podem ser úteis para pensar possíveis (re)configurações educacionais em contextos rurais na região do Baixo Tocantins/PA.

Palavras-chave: Crianças. Natureza. Mundo rural amazônico.

\section{CHILDREN AND NATURE IN AMAZONIAN RURAL CONTEXTS}

\begin{abstract}
The article deals with the coexistence of children with the Amazonian nature in amazonian rural contexts of the city of Abaetetuba-PA, supported by the idea that they are relational beings and that they constitute in connection with other beings and that potentiate activities and actions in this state of connection. This is an investigation developed in 2018 and 2019, which included bibliographic and field research, using ethnographic resources, whose centrality were interviews and observations with children, taking into account their voices and their opinions, taking them as social subjects, producers of knowledge and sociability with their peers and

1 Doutora em Ciências Sociais (UNICAMP); Professora da Faculdade de Educação e Ciências Sociais pela Universidade Federal do Pará, Campus de Abaetetuba; Coordenadora do Grupo de Pesquisa e Extensão De Bubuia Amazônica. Orcid iD: https://orcid.org/0000-0002-7466-3996. E-mail: elianapojo@ufpa.br

2 Doutora em Educação (UFPA); Professora da Faculdade de Educação pela Universidade Federal do Pará, Campus de Bragança; Vice-coordenadora do Grupo de Pesquisa e Extensão De Bubuia Amazônica. Orcid iD: https://orcid.org/0000-0003-0034-5618. E-mail: mnfreitas@ufpa.br
\end{abstract}

Revista Exitus, Santarém/PA, Vol. 12, p. 01 - 25, e022005, 2022. 
adults. As a result, it was possible to perceive that the children of these contexts have concretely a connection with the natural soil, through experiences with the mother earth and the waters, that is, there is a prospective attitude of reinvention of the cultural contents existing in the place through their games and other experiences and, at the same time, their values of living together, its traditions rich in Amazonian symbologies become educational processes in the ordinary of life. These clues may be useful to think about possible (re)educational configurations in rural contexts in the Region of Baixo Tocantins/PA.

Keywords: Children. Nature. Amazonian rural world.

\section{LOS NIÑOS Y LA NATURALEZA EN CONTEXTOS RURALES AMAZÓNICOS}

\section{RESUMEN}

El artículo aborda la convivencia de niños con la naturaleza amazónica en contextos rurales amazónicos de la ciudad de Abaetetuba-PA, apoyados en la idea de que son seres relacionales y que constituyen en conexión con otros seres y que potencian actividades y acciones en este estado de conexión. Se trata de una investigación desarrollada en 2018 y 2019, que incluyó investigación bibliográfica y de campo, utilizando recursos etnográficos, cuya centralidad fueron las entrevistas y observaciones con niños, teniendo en cuenta sus voces y sus opiniones, tomándolos como sujetos sociales, productores de conocimiento y sociabilidad con sus pares y adultos. Como resultado, fue posible percibir que los niños de estos contextos tienen concretamente una conexión con el suelo natural, a través de experiencias con la madre tierra y las aguas, es decir, existe una actitud prospectiva de reinvención de los contenidos culturales existentes en el lugar a través de sus juegos y otras experiencias y, al mismo tiempo, sus valores de convivencia, sus tradiciones ricas en simbologías amazónicas se convierten en procesos educativos en lo ordinario de la vida. Estas pistas pueden ser útiles para pensar en posibles configuraciones (re)educativas en contextos rurales en la Región de Baixo Tocantins/PA.

Palabras clave: Niños. Naturaleza. Mundo rural amazónico.

\section{INTRODUÇÃO}

Como pesquisadoras e produtoras de conhecimento, nosso desafio na docência relaciona-se com a heterogeneidade do 'mundo social' amazônico, num contínuo ensinar-e-aprender ${ }^{3} \mathrm{com}$ e sobre crianças residentes de áreas rurais. Içamos aprofundar questões relacionadas à territorialidade rural paraense sob a ótica e o cotidiano desses sujeitos em seus convívios, sociabilidades que passam pela compreensão das maneiras de ser e de viver suas infâncias, especificamente as das mesorregiões do Baixo Tocantins e do Marajó, região norte, Pará.

\footnotetext{
3 Esta forma de grafar e o sentido são de Brandão (2007).
} 
A pesquisa teve como ênfase tematizar "Crianças e infâncias em territórios rurais da Amazônia", tratando especificamente das "culturas infantis em comunidades rurais e amazoniágua"". Objetivou compreender as práticas sociais das crianças que residem em áreas rurais de Abaetetuba-PA, em seus encontros com a natureza, ou seja, significou adentrar nos saberes da cultura rural amazônica sob a ótica das crianças. Então, deu-se importância aos processos vividos por elas e às suas infâncias, significando conhecer o real de uma Amazônia que "Sob essa paisagem de rios e florestas, de ecossistemas diversos, construíram a experiência coletiva, saberes e práticas singulares que lhes permitiram viver e se reproduzir em territórios [...]" e, cujas origens, advém de sociedades indígenas e de negros no estado, até porque sabemos que os comportamentos são aprendidos e recriados por modos culturais de convívio e com as tradições que os envolvem (CASTRO, 2006, p. 148) ${ }^{5}$.

É importante ressaltar que esses sujeitos vivenciam um determinado cotidiano amazônico, interagem e recriam-se com e na cultura local; ligamse constantemente com o mundo natural dos lugares, tornando, assim, parte de suas rotinas e de seus aprendizados e, à medida que se socializam nessa dinâmica sociocultural regional, computam e percebem o mundo em meio a experiências, interações e relações com a natureza do lugar. A esse respeito, podemos citar os estudos de Brandão $(2005, \text { p. } 31)^{6}$ que demostram características de estarmos entrelaçados num circuito que "[...] continuamente estamos transformando espaços naturais, como uma beira de praia, uma ilha, um grande rio, um deserto ou uma floresta, em lugares sociais".

\footnotetext{
4 Termo criado por uma das autoras, para designar, de forma genérica, a condição amazônica de atravessamento com que vivem os sujeitos amazônicos com o mundo das águas.

5 As passagens da autora discorrem sobre a cidade de Belém, distante do município de Abaetetuba a $51 \mathrm{~km}$. Porém, vimos similitudes que julgamos bastante pertinentes, galgandoas sob novos argumentos e posições distintas, em relação às contextualidades amazônicas.

6 No texto, utilizamos sua obra nos aspectos acerca da natureza, do espaço-tempo social e natural e a perspectiva de um mútuo ensino-aprendizagem. Nesta, o autor enfatiza conceitos e proposições para um agir ambiental e, também, fundamentalmente por parte de gestores municipais.
} 
Dessa forma, acontece um profícuo processo de socialização informal e educativo que envolve o dia a dia das pessoas. No caso das crianças amazônidas, elas produzem sociabilidades enquanto relações sociais estabelecidas com seus pares e com adultos, efetuando "[...] trocas materiais e simbólicas essenciais à reprodução da cultura regional [...]" e amazônica (CASTRO, 2006, p. 15). Experienciam, igualmente, nesses contextos, uma intensa vivência nos lugares conquistados da natureza amazônica, que as ensina cotidianamente um modo de vida e a ter interesses próprios dessa cultura, humanizando-se, também, por entre os rios e suas marés, por entre as matas e suas floras, por entre quintais e plantios, por entre pontes e trapiches.

Compreender as culturas infantis produzidas por crianças de territórios rurais amazônicos, fazendo ecoar suas vozes, ouvindo-as em seus saberes e significados, desafia-nos a pensar as infâncias amazônidas sob uma outra lógica conceptual e epistemológica, o das crianças como sujeitos protagonistas de suas vidas, que pensam e agem sobre o mundo presente (GUSMÃO, 2012). Assim, o estudo tem nos conduzido a compreender acerca das valorações dadas às crianças em termos da cultura local, das políticas educacionais da região e, pontualmente, compreender as sociabilidades de tais sujeitos, levando em conta suas relações com a natureza, pois, dessa forma, constroem significados do universo amazoniágua-e-camponês a partir dessas relações e condições socioculturais.

\section{ASPECTOS TEÓRICOS-METODOLÓGICOS E DO CONTEXTO RURAL ABAETETUBENSE}

A investigação, centrada na perspectiva etnográfica, apoia-se em autores como Brandão (2007) e Fonseca (1999). Para esta última, "[...] A etnografia é calcada numa ciência do concreto, por excelência, do concreto. O ponto de partida deste método é a interação entre o pesquisador e seus seus objetos de estudo, "nativos em carne e osso" " (FONSECA, 1999, p. 58; grifos da autora). Seguindo esta premissa, o estudo abrangeu os múltiplos entrelaçamentos das culturas infantis e modos de vida 
presentes em contextos rurais de Abaetetuba - o "mundo das crianças" em plenitude -, que mistura brincares, fazeres, rotinas, ciclos de vida (BRANDÃO, 2015).

De um ponto de vista mais relacional e abrangente, a pesquisa faz interface entre antropologia e educação. Conforme aponta Gusmão (2018), - diálogo entre esses dois campos de conhecimento evidencia as potencialidades do método etnográfico, pois fornece ao sujeito de aprendizagem uma metodologia sustentada no pensar, no agir e no descobrir durante o seu decurso. Trata-se de "[...] campos científicos marcados pela interdisciplinaridade e reflexividade e pelo compromisso com realidades sociais e humanas" (p. 141).

Assim, seguimos um caminho metodológico com o uso combinado de recursos metodológicos que facilitassem a interação dialógica com os participantes de modo a construir interpretações mais abrangentes e complexas dos fenômenos de uma realidade. Exigiu computar informações, visões e os processos socioculturais vividos pelas crianças, assim como seus aprendizados de vida nos lugares. Requereu "[...] A observação, o ver, o anotar, a entrevista, a pesquisa sistemática [...]", como nos orienta Brandão (2007, p. 26), sempre com atenção às impressões dos envolvidos. Desse modo, mantivemos uma relação próxima no espaço-tempo das comunidades, buscando compreender de que forma as crianças se organizam e se relacionam com outros, como convivem no ordinário da vida naquele grupo social e, pontualmente, suas formas de expressão, seus brincares e outras narrativas que elas usam para transmitir o que sentem e o que faz parte do seu querer como criança (GUSMÃO, 2012).

Colocamo-nos na trama de uma convivência mais livre, mais pessoal com as pessoas e, em particular, com os processos vividos por crianças, grafada em um "caderno de campo" resultante de um intenso "encontro etnográfico", conforme assinala Brandão (2007). Nesse sentido, nas comunidades, o trabalho inicial de adensamento do corpus etnográfico ${ }^{7}$ da

\footnotetext{
7 Aqui entendido como todo o composto de dados produzidos, a saber: informações em documentos oficiais, registros fotográficos, de observações do/no cotidiano e anotações
} 
pesquisa se deu a partir da busca e da sistematização de dados empíricos e por estudos teóricos a partir de autores que discutem a temática e campos afins e sob um vasto levantamento bibliográfico. Tal levantamento ocorreu com autores nos respectivos eixos de discussão: o mundo rural amazônico (CASTRO, 2006), as culturas infantis (BRANDÃO, 2015; GUSMÃO, 2012), as vidas de crianças na Amazônia (POJO, 2017; MARTINS, 2014), criança e natureza (TIRIBA, 2017; BRANDÃO, 2005). Também, remetemo-nos a intelectuais da sociologia da infância, com destaque aos estudos latinoamericanos representados aqui pelos estudos de Lionetti (2018). Todos esses, sob contextos e abordagens distintas, realizam investigações que valorizam as identidades e as culturas infantis que se espraiam em diversas realidades sociais. Em suma, embebidos em referências acerca das infâncias amazônidas, estivemos nos encontrando para um "[...] conviver com outros e com o mundo, de uma maneira ou de outra nos ensinando e aprendendo" (BRANDÃO, 2005, p. 69).

Então, antes de estar com sujeitos concretos, interessava-nos ter um olhar sensivel e politicamente comprometido, bem como sobre a condução dos protocolos éticos e de aproximações exigidos, minimamente, durante uma empreitada de pesquisa que requer, também, sermos aceitos. Em campo, buscamos interagir com todos e observar as práticas sociais; e, desse jeito, as crianças foram aos poucos sendo receptivas e relacionais, configurando um processo investigativo de duas mãos, pois elas estiveram conosco muitas vezes e de várias maneiras nos espaços comunitários. $\mathrm{Na}$ análise, procedemos levando em conta aspectos macroscópicos (sistema) e microscópicos dos sujeitos em suas territorialidades, linguagens e saberes próprios.

Detidamente, para a produção de dados, realizamos o mapeamento sociocultural das localidades e das escolas; visitas às famílias; entrevistas com responsáveis de crianças, educadores e lideranças locais. Com meninos e

registradas no 'caderno de campo', as aproximações de trocas e de diálogos com interlocutores da pesquisa, bem como os diversos estudos que concernentes ao tema fizeram parte desse corpus. Logo, está presente a ideia de uma relação entre pessoas, sinalizando não somente a realização do trabalho, mas o material produzido nesse trabalho (BRANDÃO, 2007). 
meninas, utilizamos diferentes formas de interlocução e de registro por meio de desenhos, de brincares, de fotografias, de oficinas e também por meio da produção de videogravações.

Este trabalho de campo ocorreu ao longo de um período inicial de um ano nas comunidades e, posteriormente, houve visitas mais curtas no ano seguinte. E, embora já tivéssemos contato com as pessoas das comunidades, nosso foco maior esteve centrado nos pequenos, que nos forneceram um material a ser interpretado, respeitadas suas compreensões e leituras de mundo. Tal levantamento ocorreu nos anos de 2018 a 2019, envolvendo uma média de trinta e seis (36) crianças das três localidades. Dessas, participaram 14 meninos e 22 meninas, na faixa etária de 04 a 11 anos.

Passemos agora para um panorama ainda que aligeirado onde ocorreu a pesquisa, situando o ambiente amazônico do município de Abaetetuba ${ }^{8}$.

O município integra a região do Baixo Tocantins9. Localiza-se à margem direita do rio Maratauíra, um dos afluentes do estuário do rio Tocantins, sendo este, parte do estuário amazônico paraense. Em Abaetetuba, convive-se com uma relação ser humano e natureza distinta e própria! A vida humana atravessa e é atravessada pelas águas de rios, pelas cabeceiras de furos e de igarapés, pela imensa vegetação arbórea, por beiras dos cursos d'água, estradas e ramais; inclusive, tais atravessamentos são vividos também por moradores da área urbana. Trata-se de contextos que apresentam especificidades ambientais e sociais, além da estreita ordem econômica. Em termos socioculturais, esse espaço de vida e de trabalho comporta um legado expressivo no tocante à diversidade e à sociabilidade. Um exemplo, é a reprodução cultural, social e econômica das comunidades rurais, que possuem sua subsistência familiar alicerçada na

\footnotetext{
8 Área territorial de aproximadamente $1.610,652 \mathrm{Km}^{2}$ e mais ou menos 159.080 habitantes, sendo estimada uma população urbana de $58 \%$ pessoas distribuídas em 17 bairros e $42 \%$ residentes de áreas rurais, conforme dados estimados pelo IBGE (2020).

9 Fica localizada na região Norte, Pará, sendo composta por 11 municípios: Abaetetuba, Acará, Baião, Barcarena, Cametá, Igarapé-Miri, Limoeiro do Ajuru, Mocajuba, Moju, Oeiras do Pará e Tailândia.
}

Revista Exitus, Santarém/PA, Vol. 12, p. 01 - 25, e022005, 2022. 
produção que mescla o extrativismo vegetal e animal, a agricultura da mandioca, a olaria, o artesanato em madeira e cipós etc.

Outra menção importante à cidade são suas lutas e as contribuições de grupos diversos e idiossincráticos, chamados de remanescentes. Para ilustrar, existem algumas comunidades cujos nomes e territórios marcam tal reminiscência como os quilombolas das ilhas, de estradas e ramais; os ribeirinhos, os agroextrativistas, os assentados ${ }^{10}$.

No caso das comunidades, locus da pesquisa, levamos em consideração: a) o município ser predominante rurall1; b) possuir comunidades ou territórios diversos; c) ter considerável quantitativo de crianças em áreas rurais; d) já ter realizado outros estudos nas comunidades; e) aproximação com o trabalho pedagógico com crianças.

As comunidades Cujari, Jarumã e Campompema são de terras entrecortadas pela dinâmica das águas com seus distintos rios, furos e igarapés ${ }^{12}$, além de ficarem próximas ou integrarem alguma ilha da cidade, como é o caso da comunidade Campompema. As outras duas comunidades, Cujari e Jaumã, estão tipificadas como agroextrativista e rural. São territórios tradicionais conhecidos popularmente como áreas rurais, do "interior", de "sítio", os quais possuem uma série de direitos como o reconhecimento de viver nos territórios que, tradicionalmente, ocupam.

$\mathrm{Na}$ verdade, preocupamo-nos com a totalidade da vida social dessas comunidades, na medida em que crianças e adultos se misturam na vida cotidiana em suas formas interativas brincante, laboral e comunitária (BRANDÃO, 2007).

Em termos gerais, as crianças que participaram da pesquisa moram e estudam em escolas municipais situadas nessas comunidades; participam ativamente, aos fins de semana, das atividades nas igrejas evangélicas ou na católica existentes; algumas vivem com seus genitores e outras, geralmente, com os avós. No tocante à circularidade no ambiente natural,

\footnotetext{
10 Sobre tais identificações, consultar Castro (2006) e Pojo (2017).

11 Ver, a respeito, o trabalho de Bastos (2010), referenciado ao final deste trabalho.

12 Circundam tais comunidades, os seguintes: rios Jarumã, Campompema e Arienga; igarapés Cujari e Cuminquara e, os furos Galinha e Acaraqui.
} 
observamos que a maioria de suas práticas e demais interações acontecem nos quintais das propriedades e de "pés no chão", são brincares preferidos o tacobol e o pira esconde.

Atualmente, amparado por legislações e concepções, considera-se a criança como sujeito de direitos. Nesse sentido, os estudos antropológicos e educacionais apontam em suas pesquisas a defesa do quanto esses sujeitos são potentes em alegria, sinceridade e formas socializáveis singulares, ou seja, elas têm um lugar social próprio, pois "[...] sabem de si, sabem onde estão, o que faz parte de suas vidas; conhecem seu mundo; e se confrontam com os princípios de pertença e identidade que thes são atribuídos" (GUSMÃO, 2012, p. 164). Acreditando nesse potencial criativo, na pesquisa, colocamo-nos não somente a dialogar com elas, mas substantivamente a conhecer suas culturas de encontro com a natureza do lugar que ocorrem por entre relações escolares, de vizinhança e de convívios no cotidiano das comunidades.

E este contínuo, mover-se no contexto faz com que as crianças circulem nos ambientes naturais, incluindo observarem a beleza das flores, tomarem banho de chuva e no rio, cultivarem uma horta, praticarem o plantar e o colher frutos, subirem em árvores etc. Experimentam a condição de uma infante com movimentos e com vivências sensórias diversos, pois elas, no cotidiano de suas famílias, desde a mais tenra idade, ingressam nas margens intrincadas de furos e de igarapés, das matas, dos quintais e dos caminhos, espaços, esses, palcos do brincar-aprender na natureza do lugar. Para as crianças, o abecedário camponês e florestal segue as estações do verão e do inverno amazônicos, das chuvas e de intenso sol, dos ventos e das poeiras, dos fins de semana ou não, promovendo aprendizagens, experimentando, interagindo e descobrindo o mundo que o cerca. Ao mesmo tempo, esses meninos e meninas, carregam processos de invisibilidade e até de descaso; suas vozes, seus sonhos e suas necessidades nem sempre são levados a sério, embora carreguem consigo todo esse arsenal de conhecimento e de experiência. 
Mesmo com os direitos da criança e do adolescente previstos em lei, convém mencionar que ainda assim são presentes e dolorosas as situações de violação pelas quais passam, de modo geral, as crianças amazônidas, que têm seus direitos, por diversas vezes, negligenciados, ou seja, eles e elas carregam, em suas vidas, a imbricação natureza-criança em toda sua diversidade amazônica, e, por outro lado, as contrariedades que as impedem de viverem, plenamente, suas infâncias, e com dignidade.

Aqui cabe o destaque com as semelhanças de desumanização por que passam as crianças do Marajó no Pará, pormenorizadas na pesquisa de Andrade e Pacheco (2016). Também, na região tocantina, presenciam-se situações de crianças em condições de trabalho infantil, de uma infância marcada pela pobreza, de baixo rendimento escolar, de famílias que sobrevivem basicamente da renda do Bolsa Família; enfim, elas enfrentam a escassez de serviços públicos. Esse é um dado objetivo das condições existenciais de centenas de crianças dessa região, sejam elas de contextos urbanos ou rurais, sejam de território ribeirinho ou quilombola, sejam assentadas ou indígenas. E mais, no Relatório sobre Pobreza na Infância e na Adolescência,

Os dados mostram que, segundo a Pnad 2015 (Pesquisa Nacional por Amostra de Domicílios), a população de crianças e adolescentes do campo sofrem mais privações do que quem vive nas cidades. $O$ percentual de meninas e meninos da zona rural que não têm seus direitos garantidos é o dobro daquele nas áreas urbanas (UNICEF, 2018, p. 14).

Ainda, nos estudos de José de Souza Martins (2014), tratando de crianças, o autor confirma que elas apresentam características peculiares e, utilizando-se de depoimentos, apresenta um pouco da condição fronteiriça da Amazônia, sendo criança num espaço social que se processa por conflitos armados entre posseiros e grileiros. A fala da menina Regimar, descrita como "miúda e arrumadinha", põe em relevo o fato de a migração não se justificar apenas pela busca de terra, mas também e, simultaneamente, se justifica pela fuga da humilhação sofrida no presente. No passado e no futuro, busca-se um lugar que seja "bom para o pobre viver sua pobreza".

Revista Exitus, Santarém/PA, Vol. 12, p. 01 - 25, e022005, 2022. 
Voltando à região tocantina, chama atenção a imbricação trabalho e vida infantil. É comum o envolvimento das crianças nas atividades laborais que são exercidas por seus responsáveis, tais como os fazeres da roça e do retiro, tarefas domésticas, apanhação do açaí, pesca artesanal, além de as meninas cuidarem dos irmãos menores em muitos casos. Um exemplo concreto são as crianças que frequentam a feira da cidade de Abaetetuba. Elas acompanham seus avós (sendo netos ou não), com a missão de ajudálos na tarefa de carregar as compras.

Para nós, na Amazônia paraense, são produzidas infâncias plurais. Tal reconhecimento parte da constatação de que o oferecimento e o acesso aos serviços públicos destinados às crianças têm sido marcados por desigualdades atravessadas por questões étnicas, de classe e regionais, conforme demonstram pesquisas de Rosemberg (2008). E, no que se refere à questão territorial amazônica, num processo de múltiplas desigualdades, as populações do campo, particularmente, ainda convivem com muitas ausências de políticas públicas, fruto, inclusive, do tipo de desenvolvimento pensado para a região, que foi basicamente construído e executado visando à exploração dos recursos naturais e toda sua complexa biodiversidade, mas que em nada tem contribuído de forma positiva à vida dessa população. Para Castro (2006, p. 15), as regiões paraenses representam

[...] espaços de constituição da sociedade colonial com todas as suas contradições, diferenças sociais e étnicas, e onde se forja uma cultura que interioriza as relações com o espaço das águas e dos recursos florestais, base da constituição da economia regional.

Ressalta-se que tal organização socioeconômica regional destoante é bastante atual. Existem, concretamente, diversos conflitos socioculturais e econômicos; uma diversidade cultural e de grupos étnicos com seus territórios de vida e de existência que, no âmbito das políticas públicas, não são pensadas a partir dessas perspectivas. No que tange às crianças abaetetubenses, e com base nos dados territoriais, suas garantias de vida digna ainda são um devir, quando pensado em termos de aprender e ser feliz. 
Baseado nessa dinâmica social amazônida, ousamos a fazer ecoar as vozes, as expressões e os modos de vida das crianças, cujas infâncias se movem e se constroem nesses espaços de ribeirinhos, quilombolas, rurais etc. e, dessa forma, vão tecendo suas histórias, seus processos educativos e culturais próprios, pois estamos convencidas de que

[...] a criança e a infância que lhe é própria são também o enigma que nos desafia, desafia nosso conhecimento e nos coloca diante da circunstância de ter que admitir que não sabemos tudo, não detemos todo o conhecimento disponível sobre a realidade e as coisas (GUSMÃO, 2012, p. 175).

Em suma, além de existirem, concretamente, os desafios da vasta extensão territorial da região amazônica e tocantina, exemplificados pela dinâmica geográfica de Abaetetuba, soma-se ainda a isso uma extensão de realidades socioculturais que afetam diretamente as crianças, resultantes do descaso com suas infâncias no seu todo, o que exige de todos uma atuação coletiva e responsável frente aos desafios postos. Há de se empreitar esforços com e junto dos diversos campos-setores, visando a garantir vida digna para essa primeira infância. Daí porque a infância amazônida paraense precisa ser estudada, pesquisada e visibilizada nas ações no que tange à garantia de saúde, de lazer, de educação, de cultura.

\section{A CRIANÇA E A NATUREZA AMAZÔNICA}

Somos sabedores que "[...] nós vivermos no mundo e lidarmos com a natureza de que somos parte, faz parte de algo que é nosso e tem a nossa marca na Terra". Habitamos "[...] em um Mundo de Natureza coletiva e socialmente transformado em um Mundo de Cultura" (BRANDÃO, 2005, p. 31). Vive-se numa diferenciada experiência com espaços da natureza, transformados em um lugar social. Especialmente, no Pará, convive-se com todo um conjunto paisagístico, cultural e de seres vivos que constitui a singular natureza amazônica, sendo esta lógica natural e de cunho ambiental, formado por: "[...] sistemas culturais de saberes, valores e sensibilidades a respeito da natureza e das múltiplas maneiras como os seus 
elementos naturais e os seres vivos interagem e se relacionam", como menciona Brandão (2005, p. 74, grifos do autor).

O ser humano é parte integrante do ambiente natural, compartindo espaço junto dos vários elementos, como a fauna, a flora etc. Ele habita, reproduz-se e produz com e em uma cultura própria, ou seja, ao mesmo tempo em que o ser humano é parte da natureza, ele a modifica. Essa forma de conceber a natureza pode ser inteiramente associada ao ambiente do homem e da mulher mencionados aqui, que vivem integrados à natureza do lugar, utilizando dos meios naturais para a sua sobrevivência.

Tomando o real vivido, essas populações vivenciam realidades próprias, mediadas pelo território. Elas se harmonizam com o movimento da natureza, seja pela temporalidade ou pela territorialidade das águas e do clima peculiar da Amazônia, seja por toda uma geografia de terras que entrecortam pontes, ramais e estradas. Todos esses fatores decorrem de processos socioculturais, econômicos e ambientais peculiares a esses contextos campesinos. De outra forma, espraia-se um tipo de mobilidade e de produção de vida bastante aliado ao tempo da natureza amazônica e local.

Precisamente, sobre criança e natureza, as contribuições da estudiosa da infância Léa Tiriba (2017) são valiosas, sobretudo, no sentido de um novo olhar e de outros caminhos para o fazer cotidiano de pessoas dedicadas à educação de e com as crianças. Em sua visão, "As crianças se lançam à natureza porque, como todos os seres vivos, estar nela thes assegura permanecerem sendo o que são, sendo o que as constitui" (TIRIBA, 2017, p. 75). Vale ressaltar que hoje em dia já aprendemos um pouco mais sobre a criança de um modo mais integrado e aprofundado, envolvendo toda a dinâmica da vida social em dimensões diversas, afetiva, psicológica e sociocultural.

Com base nos dados do material etnográfico, percebemos o quanto elas aprendem cotidianamente na natureza do lugar, fazendo coisas, transitando nos arredores e participando de rotinas que envolvem tarefas escolares, de ajuda familiar e de brincar. Com as águas, por exemplo, elas 
espiam e dizem com firmeza sobre as marés em suas cheias e vazantes; sobre a casa vizinha do rio e do sentir-se como um barco ancorado em suas águas. Essas ligações dizem muito dos sujeitos com o que o rio apresenta.

Na terra, as crianças aprendem em companhia de adultos e de outras crianças não apenas nomes, usos e características de árvores, plantas e animais, mas também andarilham nos espaços laborais das roças, dos roçados e de retiros; aprendem dos tipos de cultivares, dos utensílios utilizados nos afazeres, do crescimento dos cultivos; identificam os donos das propriedades bem como têm noções sobre os processos de gestão das tarefas laborais agroextrativista.

Corroborando com essa força interativa descrita acima, temos a ideia de que nesses e noutros espaços naturais elas aprendem informalmente a entender e a se relacionar com tais espaços e com todo um conhecimento que o ambiente amazônico pode proporcionar; conectam-se, ainda, com as belíssimas histórias lendárias, com os simbolismos e com as paisagens que o ambiente irradia, apenas por estarem lá, indo e vindo, no espaço-tempo dos lugares.

O movimento livre ou acompanhado na comunidade é importante como uma forma de ensinar-e-aprender um saber prático. Permite às crianças observarem a natureza e a dominarem saberes e terem destreza no agir. Nessa experiência, brincam e convivem naturalmente nos espaços de trabalho; assim, é comum elas "ajudarem' seus pais e, dessa forma, aprenderem praticando diferentes tarefas, tipo apanhar açaí, arrancar mandioca, carregar água ou remar. Por estas relações com a natureza e por circularem nos espaços, as crianças desenvolvem uma escuta sensível com o ambiente natural, uma percepção sobre o lugar onde moram e, em meio $a$ isso tudo, sabemos o quão importante é que elas vivam uma aproximação com o lugar, pois aprenderão a reconhecer esse espaço como parte de sua vida e de sua experiência.

Essa é uma sensibilidade ambiental que advém da ação dos adultos que possuem essa herança ancestral de conhecimentos sobre a vida rural, 
sem contar que estão sempre investindo no cuidado com a natureza do lugar, pois são fundamentais para suas atividades produtivas e cotidianas.

O usufruto junto dos espaços naturais promove um relacionamento que ora é afetivo com a natureza, ora é de apropriação, evidenciando elos perenes e que refletem intensamente as práticas sociais nesses espaços de convivência. Refletem a influência constante dos sujeitos com a dinâmica rural amazônica e toda uma tradição, sendo experiências que comportam memórias, significações e intertrocas construídas a partir da conexão culturanatureza, como parte da fluidez amazônica paraense. Há, concretamente, uma condição fronteiriça com algum rio e com as águas, bem como com a terra, já que são partes da vida do sujeito amazônico.

Não podemos deixar de mencionar que, em consequência do processo de globalização, cada vez mais se investe na cultura hegemônica, deixando de lado a cultura local. Esta, por vezes, é considerada 'menos atrativa' e lucrativa, gerando com isso consequências danosas para qualquer processo identitário, ambiental e local. Cada vez mais a natureza é vista separada dos seres humanos e, como consequência, convivemos com intenso processo de desequilíbrio ambiental, uma crescente desigualdade social etc. Ao mesmo tempo, a natureza de um território fala por nós, é um documento vivo de um povo, de uma comunidade, logo, valorizá-la significa - avivamento de práticas tradicionais como a da agricultura e de manifestações culturais diversas e singulares, como os brincares tradicionais de crianças. Afinal, somos seres construídos culturalmente e educados mutuamente em cada comunidade/lugar/povo.

\section{SOCIABILIDADES VIVIDAS POR CRIANÇAS}

Diferente da condição de adulto, as crianças nos diferentes cenários naturais e por formas interativas de um "mundo à parte", produzem suas infâncias nesses contextos amazônicos (BRANDÃO, 2015; POJO, 2017). Suas práticas de convívio integram-se ao cotidiano dessas populações, evidenciando 
dos símbolos e dos saberes-valores apropriados de fragmentos da cultura adulta e reinventados em suas endiabradas e encantadoras culturas infantis (BRANDÃO, 2015, p. 111, grifos do autor).

Em áreas rurais de Abaetetuba, o "mundo à parte" das crianças inclui a participação delas nos brincares, na experiência escolar, na igreja e transmitem valores, símbolos e significados do/ao mundo. A partir disso, os vários aspectos que constituem as infâncias dessas crianças são importantes para compreender um pouco mais sobre seus mundos reais vividos, seus processos vitais e identitários (POJO, 2017), à medida em que tais sujeitos são potenciais na "[...] invenção dos seus cotidianos, dia a dia, ciclo a ciclo" (BRANDÃO, 2015). Significa, então, à luz de seus mundos infantis, entender o lugar social desses sujeitos em mediação com toda uma ancestralidade amazônica em sua diversidade.

Em suas práticas infantis, destaca-se o exercício constante da oralidade como mecanismo de perpetuação de um modo de vida nos territórios, com ritmos e jeitos próprios. Transmitir suas vivências e ideias por meio de causos, histórias e tantas outras narrativas é algo peculiar no cotidiano das comunidades, o que se traduz em tempos de risos, de gargalhadas, de condições afetivas expressas na fala, no corpo. Da ação à representação, de múltiplas formas e meios, da escrita à oralidade, elas transmitem posições, afetos etc. Nesse caso, sua oralidade é produtora de significados expressos também por meio de desenhos, de perguntas, de uma arte ou de uma pintura, de um convite ao brincar.

No entanto, existe toda uma forma de negação de sua fala que porfia com a luta, das crianças, por brechas para tagarelar, para transgredir a ordem do 'silêncio'. Nesse aspecto, concordamos com o que diz Gusmão (2012, p.164), pois vivemos em uma

[...] sociedade da escrita que caça a palavra de quem é menos, que não o deixa falar, não é - nem pode ser - absoluta em seus propósitos. Mostra que, tendo-lhe sido negado o direito a uma vida plena, ela, criança, encontra outras formas de expressar o que sente. 
A oralidade da criança mostra sua condição de libertação, de ruptura e de transmissão de suas "cem linguagens"13. Expressa, de fato, o seu sentir, o seu pensar, o seu fazer e o seu agir, o seu modo de ser e de viver em Abaetetuba, na Amazônia. São exemplos as explicações acerca da natureza, captadas durante momentos com elas, nos espaços dos quintais, das ruas, dos caminhos e das beiras, conforme transcritos no quadro abaixo:

QUADRO 01: Sobre a Natureza

\begin{tabular}{|ll|}
\hline \multicolumn{1}{|c|}{ Aspectos } & Relatos de saber \\
\hline O que é? & $\begin{array}{l}\text { A natureza é onde a gente vive, essa mata toda aí que a gente faz casa e } \\
\text { até essa Vila. É onde os bichos, passarinhos ficam que é a casa deles, nas } \\
\text { árvores (Susana Moraes, } 5 \text { anos, Campompema). } \\
\text { Na natureza tem bichos perigosos. Eu tenho medo de cobras, mas é o meu } \\
\text { lugar preferido (Enderson Vidal, } 6 \text { anos, Jarumã). }\end{array}$ \\
\hline $\begin{array}{l}\text { Elementos } \\
\text { naturais }\end{array}$ & $\begin{array}{l}\text { São bonitas as árvores e as plantinhas, e, ao brincar de comidinha, uso as } \\
\text { folhas como minhas panelinhas. Só tenho medo dos bichos que ficam } \\
\text { escondidos dentro do mato, por isso prefiro brincar no quintal (Beatriz Silva, } 6 \\
\text { anos, Jarumã). }\end{array}$ \\
\hline $\begin{array}{l}\text { Tudo } \\
\text { interligado }\end{array}$ & $\begin{array}{l}\text { Queria morar sozinha em uma casa no meio da floresta para brincar com os } \\
\text { animais e ia convidar crianças para virem visitar o mato. Lá tem onça, leão, } \\
\text { tigre, macaco e um monte de outros bichos, que com a gente (Alana Moraes, } \\
5 \text { anos, Cujari) }\end{array}$ \\
\hline
\end{tabular}

Fonte: Pesquisa de campo, 2018-2019. Org. Eliana Pojo, 2021.

Seus dizeres expressam relações, associações e sentimentos vividos nos espaços naturais, que acentuam um tipo de valorização do meio, conforme constamos nos relatos.

A expressão Queria morar sozinha em uma casa no meio da floresta para brincar com os animais e ia convidar crianças para virem visitar o mato é elucidativa de uma outra dimensão, ressaltada pelos pequenos: a da natureza viva da vida diária; esta marcada pelo relógio do brincar e espraiado nos lugares, nas rotinas, no ambiente do quintal ou do terreiro em dia de sol ou de chuva, de dia ou de noite, com adultos ou entre menores etc. E a tal natureza onde a gente vive, que se imbrica com os tempos (do brincar e da própria natureza) faz com que as crianças se aproximem do mato e dos bichos; faz com que estejam na terra e por entre as folhagens; faz com que ouçam o canto dos pássaros, e, dessa forma, a vida delas vai

13 Termo adotado por Loris Malaguzzi.

Revista Exitus, Santarém/PA, Vol. 12, p. 01 - 25, e022005, 2022. 
sendo recriada, transformando-se e se religando, harmonicamente, com a natureza.

\section{Por aqui ainda se vive com os pés descalços}

Durante as idas e vindas às comunidades, vimos o quanto a terra é também um cenário de interações positivas entre os moradores, a partir do que Ihes é comum, como, por exemplo, identificar os murmúrios de grilos. Por aqui, as crianças repetem experiências de tomar banho na chuva, cantarolar na grama ou debaixo das árvores, correr no mato, fazer disputas de pega-pega, construir casinhas com paus e gravetos, e com adultos, 0 balanço feito com aro de bicicleta pendurado numa árvore. Por aqui, os pequenos se reúnem em um local espaçoso para empinar pipa ou jogar no celular.

Na localidade de Campompema, Mikael dos Santos ( 6 anos), em diálogo conosco, informou-nos que acha muito legal sentir o vento e ver as folhas caindo das árvores no terreiro de sua casa, e que nesse espaço [...] brinca com seu primo de se sujar na terra e de pegar folhas secas para fazer bolinhas com o barro mole. Neste aspecto, faz sentido o "habitar-brincando" das crianças, em que a natureza é percebida como espaço e como instrumento. As pessoas não consideram somente o seu aspecto físico, pois, ao contrário, conviver com a terra e sentir os pés no chão são significações que comportam as muitas práticas sociais daquele modo de vida. Segundo Pojo (2017, p. 77, grifos da autora),

[...] O 'povo do campo' costuma dizer: nesse lugar criei meus filhos e tiro meu sustento; nessa terra tudo dá. Esses são fragmentos de falas repetidas e estão imbuídos de valoração e não apenas referente à sua utilidade. Esse povo vive entre práticas do comer, do comunicar, do trabalhar, do emprestar/emprestar-se na precisão e aquele é também um canal e transmissor de saberes. As pessoas não consideram somente o aspecto físico pois, ao contrário, ali está a terra, o espaço das muitas práticas sociais do viver.

Ou seja, a terra manifesta-se como campo fértil do processo identitário dos grupos nas respectivas comunidades. Ao mesmo tempo, tais momentos indicam a autonomia de meninos e de meninas, uma vez que nem sempre 
estão sob a tutela de seus pais ou de outros adultos, mas cuidam uns dos outros e se envolvem em atividades próprias, geralmente fora de casa.

\section{Por aqui ainda têm quintais amazônicos}

Ainda nessa configuração social e cultural, os 'mundos' infantis são experienciados nos quintais das propriedades dos seus responsáveis, que se configuram espaços representativos do mundo amazônico na ilharga das residências e de fácil acesso. Nos territórios rurais de Abaetetuba, eles são parte da cultura local, sendo perpetrada até os dias atuais e, cujo espaço possui jardins, árvores frutíferas e plantas medicinais; neles se plantam manivas, criam-se galinhas, cachorros, coelhos ou patos; neles, observam-se os cantos dos pássaros, e, às sombras das árvores, adultos e crianças conversam nos fins de tarde.

Os quintais combinam com as crianças, talvez por isso Brandão (2015, p. 112) tenha assinalado que eles são espaços da gratuidade infantil, "[...] os fundos dos quintais (quanto mais misteriosos, mais cheios de árvores, de cantos "escondidos" e de trastes velhos, melhor) [...]". Neles, quase tudo pode se tornar brinquedo ou uma brincadeira. Galhos, folhas, flores, cascas de frutas, árvores, lama, bola, pedras, pedaços de pau, cachos do açaizeiro, talas, caroços, poças d'água e tantos outros, como se nada pudesse parar a imensidão criativa de uma criança. Tudo o que puder ser visualizado dentro do limite de um quintal, pode ser útil para o que os pequenos desejam ser em um determinado momento, seja dona de casa, seja mãe de bonecas, seja jogador de futebol, seja rabeteiro ou agricultor; um ser livre que pode subir ou se esconder em árvores, um lugar onde seu amigo pode ficar camuflado nas plantas ou ser dono de um pedaço do céu com sua pipa. Muito do que está disponível na natureza, provavelmente, a criança encontra formas de usufruir.

São espaços do brincar de crianças na vizinhança que em alguns momentos alegram, em outros, testam a paciência dos adultos, pois folhas são arrancadas, galhos são quebrados, bolas são arremessadas nos telhados e tantas outras traquinagens são feitas. 
Em Abaetetuba, esses espaços são estreitos, outros grandes e sem cerca; possuem um clima agradável. Nesse espaço do vizinho ou da própria criança, muitas vezes, vive-se o chão que alimenta uma infância com possibilidades inventivas de lazer e de brincar, de laços de amizade e de respeito com o humano e com o não-humano. Espaço que, para os mais antigos, ajuda a criança a crescer saudável e resistente a qualquer doença, porque se pisa na terra. Espaço no qual se observa a pressa da criança em se sentir viva, dona de suas rédeas, mesmo que por poucas horas, brincando ou fazendo tantas outras coisas.

\section{Brincares}

O brincar da criança é o eixo central de sua experiência pessoal, familiar (entre irmãos) e grupal (dentro de grupos de idade e de grupos de interesse) de vida. Ele equivale à obsessiva importância que damos ao trabalhar nas culturas dos adultos (BRANDÃO, 2015, p. 113, grifos do autor).

Trouxemos a epígrafe acima, extraída do artigo "Olhar o mundo e ver a criança: Ideias e imagens sobre ciclos de vida e círculo de cultura" (BRANDÃO, 2015), pois esse relato abarca a essência dos princípios, de uma compreensão das crianças, tomando-as como atores de conteúdos culturais específicos. Interpretamos, por esta assertiva, o brincar como sendo um trabalho educativo; e, aqui, nesse mundo rural amazônico, a brincadeira acontece a todo o momento, seja ao realizar alguma tarefa ou até mesmo na rua, no barco, na ponte, no caminho ou no ramal, tudo são peraltices e há sempre motivos para a diversão, de modo individual ou coletivo.

Os brincares de adultos e, potencialmente, das crianças, misturam-se com o ambiente arborizado e nas áreas verdes, bem como nos espaços das margens dos rios para os que moram em contextos ribeirinhos, por exemplo. Nesse sentido, as crianças agem culturalmente e, na cultura, por meio do brincar, como é enfatizado na epígrafe do autor.

O brincar configura um ato cultural e político, pois por meio desse mundo brincante passamos a conhecer as condições de existência de meninos e de meninas, até porque, concordando com Brandão (2015, p. 117, grifos do autor), 
[...] as pessoas e sobretudo as crianças com quem lidamos não são seres abstratos, moradores de mundos idealizados e que podem ser, portanto, compreendidas de maneira geral [...], ao contrário disso, a realidade de muitas delas é bem diferente do que pensamos.

Em síntese, seus brincares são criações e repetições expressas por meio de pipas, caminhãozinho de madeira ou lata, piões, petecas, casa e comidinha com folhas, canoagem e banhos de rio. Por essas interações, as crianças brincantes vivem uma profícua convivência social com outros (sejam eles irmãos, primos, vizinhos) e com adultos. Vivem uma profícua ligação com a natureza amazônica, conforme ilustra, mais uma vez, os conteúdos manifestos de suas raízes crianceiras, especialmente, na terra:

QUADRO 02: Os múltiplos processos do brincar na terra

\begin{tabular}{|c|c|c|}
\hline Brincar/brinquedo & Brinquedo/Recursos & Espaços \\
\hline $\begin{array}{l}\text { Andar de bicicleta, de subir } \\
\text { em árvores, no balanço. }\end{array}$ & $\begin{array}{l}\text { - bicicleta, cordas. } \\
\text { - árvores, caroços de açaí, } \\
\text { talas de miriti etc. }\end{array}$ & $\begin{array}{l}\text { rua, quintal, campo de } \\
\text { futebol, área livre, ramal, } \\
\text { caminho. }\end{array}$ \\
\hline $\begin{array}{l}\text { Comidinha, de casinha, de } \\
\text { mãe e filha de boneca, de } \\
\text { salão de beleza, de } \\
\text { professora, de estar na } \\
\text { escola, de ser cozinheira, de } \\
\text { pescar, de jogar pedras, de } \\
\text { carrinho, de fazer bolinha de } \\
\text { sabão, de cozinhar com } \\
\text { massinhas. } \\
\text { Bola, de futebol, de pipa, } \\
\text { pira-pega, pique-pega, } \\
\text { amarelinha, pira-esconde, } \\
\text { pira garrafão, pique- } \\
\text { esconde, tacobol, cemitério, } \\
\text { peteca, queimada, cabo } \\
\text { de guerra, de toque, de } \\
\text { esconderijo, de correr. }\end{array}$ & $\begin{array}{l}\text { - carrinho, boneca, } \\
\text { panelinha. } \\
\text { - água, terra, folhas, flores, } \\
\text { galhos, pedaços de tijolo e } \\
\text { etc. } \\
\text {-outros: sabão, balde, } \\
\text { barquinhos de papel, } \\
\text { celulares. } \\
\text { - bola (feitas de papel, } \\
\text { areia, sacola), pipa, garrafas } \\
\text { etc. } \\
\text {-árvores, tacos, bancos e } \\
\text { pedaços de madeira etc. }\end{array}$ & $\begin{array}{l}\text { rua, quintal, campo de } \\
\text { futebol, ramal, caminho. }\end{array}$ \\
\hline
\end{tabular}

Aspectos

Brincar movimenta

Brinco pulando no balanço, lá no campo. No galapé, mas só com boia. No ramal de correr e de biciqueta (Rennê Santana, 04 anos, Cuajii).

Eu costumava brincar no porto do homem onde dava pra brincar no rio. Também, costumo brincar dentro de casa e na rua com meus amigos (João Silva, 06 anos, Campompema).

Jogar bola, porque eu gosto de correr e fazer gols (Milton Pires, 5 anos, Jarumã).

Brincar diverte 


\begin{tabular}{ll}
\hline & gente mais gosta: correr, pular, rir e gritar também (rs). É muito \\
divertido fazer isso (Heloise Trindade, 6 anos, Campompema). \\
Era uma vez um camarão gigante e, a titia, estava apanhando açaí. \\
Aí, tinha muita abelha no cacho de açaí, elas correram atrás da titia, \\
que pulou na água e o camarão gigante comeu as abelhas ra ra ra \\
(Enderson Figueiró, 6 anos, Jarumã) \\
Brincar de subir na árvore para pegar a menor folha, quem pegar a \\
menor folha faz ponto e, quem fizer mais ponto, ganha (crianças do \\
Cujari). \\
Brincar de comidinha de mentirinha. Porque penso que eu sou a \\
mamãe fazendo comida, que ela aprende na televisão (Beatriz \\
Carvalho, 6 anos, Jarumã). \\
Brincar é divertido, porque eu posso fazer o que eu quiser com os \\
meus brinquedos, faço um montão de coisas! Eu quero brincar o dia \\
todo, mas minha mãe não deixa, ela me chama para fazer o dever \\
da escola. Ela fala que tem hora de brincar e hora de fazer o dever. \\
Mas eu gosto mais da hora de brincar rsrsrs...! A gente pega aquelas \\
pedrinhas e constrói robôs e pista de carrinhos! (Asafe Sousa, 06 anos, \\
Cujari). \\
Eu gosto de brincar desenhando o passarinho, o filhinho do \\
passarinho, o pai e a mãe dele, o irmão e o cachorrinho do tio dele \\
(Taylom Airis, 5 anos, Jarumã). \\
Gosto de brincar na casa de praia do meu avô lá na ilha Trambioca. \\
Eu amo esse lugar, lá posso correr, pular e tomar banho. Lá, sou uma \\
sereia do mar (Maria Julia Coutinho, 5 anos, Jarumã)
\end{tabular}

Fonte: Pesquisa de campo, 2018-2019. Org. Eliana Pojo, 2021.

Na visão das crianças, os espaços são infinitos e de uma imensidão explorável conforme demonstram suas invenções brincantes, citadas em seus relatos. O quintal, a rua, o caminho ou qualquer outro espaço livre são úteis para brincarem. Elas vão arquitetando e formalizando as regras, os elementos, os tempos, os grupos. Assim, as brincadeiras ganham sentido próprio naquele contexto e naquele grupo brincante. Vale dizer que os encontros entre os pares tornam tudo mais rico, mais singelo, ou mais complexo dependendo das relações que ali estão estabelecidas.

Para fechar esta seção, é descrito mais um brincar, expressão de suas ideias e preferências.

\section{Taco ou tacobol}

Para esta brincadeira, é necessário que se tenha pelo menos quatro pessoas, formando duas duplas, e o espaço precisa ser um lugar que dê liberdade aos participantes para correrem, de preferência ao ar livre, para que a bola possa ser rebatida. Os objetos são: garrafas de plástico; pedaços 
de madeira; bola (esta, por vezes, é confeccionada com papel e com sacola plástica). Brinca-se assim: em lados opostos, uma dupla ficará com o taco (geralmente, é um pedaço de pau) para que possa defender as garrafas. A outra dupla, posicionada atrás das garrafas, ficará com a bola. Os rebatedores, que são a dupla que tiver o taco, o colocam na frente da garrafa para protegê-la do lançamento da dupla adversária, que estará com a bola. O objetivo da dupla de lançadores é derrubar a garrafa do adversário com a bolinha, e dos rebatedores é atingir a bola o máximo de vezes possível, lançando-a bem longe. Se um dos jogadores que estiver com o taco conseguir rebater a bola para longe, os arremessadores devem correr para pegá-la. Enquanto um dos componentes não volta com a bola, os jogadores do taco cruzam a distância entre as duas garrafas trocando de lugar com sua dupla e, tocando o instrumento (os tacos) entre si. Quanto mais vezes os tacos forem cruzados, mais pontos são marcados. Geralmente, define-se um limite 100 de pontos para considerar uma dupla vitoriosa. Se os arremessadores conseguirem quebrar a defesa dos rebatedores e derrubar a garrafa, as duplas trocam de posição, e, assim, a partida prossegue até a primeira dupla atingir a pontuação limite.

\section{CONSIDERAÇÕES FINAIS}

Buscamos com este trabalho elucidar a humanização de meninos e de meninas na importante (re)ligação com a natureza do lugar, em seu valor político e de uma temporalidade infantil, de rebeldia e de transgressão, como parte sociocultural de um mundo próprio.

Todo o conjunto de fazeres-saberes desses sujeitos nos diversificados cenários rurais amazônicos, aqui mencionados, nos remete ao que vem nos ensinando Brandão (2005, p. 72, grifos do autor): "[...] na verdade da vida social, cada "tipo cultural de saber" e cada "unidade pessoal de saber" (cada uma ou um de nós) sempre criam, renovam, guardam e convivem com os outros a partir de eixos e feixes de conhecimentos próprios e pessoais". Nessa perspectiva, tomando a lógica dos interlocutores da pesquisa, as crianças, vemos que se criam e se recriam inúmeras 
possibilidades de interligarem-se à natureza, embrenhando-se nas vivências junto da mãe terra e das águas, nas praias, nas margens de rios, de furos e de igarapés, ou seja, há por tais sujeitos (com seus brincares e outras experiências culturais) uma atitude prospectiva de reinvenção dos conteúdos culturais existentes no lugar, consequência não apenas de razões práticas de gestão de um "mundo infantil" por estas, mas, também, por uma curiosidade que os move e que os coloca na condição de 'atravessados' à natureza do lugar; ao mesmo tempo, seus valores do conviver e suas tradições, ricas de simbologias amazônicas, convertem-se em processos educativos no ordinário da vida.

$\mathrm{Na}$ pesquisa, detidamente, esse processo educativo culturalmente construído se deu pela escuta das crianças e por suas produções infantis através de desenhos e de depoimentos, de brincares e de travessuras etc., confirmando a importância de ouvi-las, pois elas têm muito a nos ensinar, sem contar no quanto elas ficam felizes quando percebem que um adulto está interessado no que elas fazem, sabem, pensam, sentem. Assim, devagar, captamos um pouco do real significado de as crianças estarem para a infância, do quanto elas nos educam em suas rotinas sobre não maltratar os rios, as árvores, as matas, e com seus convívios interativos, mencionados ao longo do texto.

As aprendizagens de crianças residentes de áreas rurais em grupos de diferentes faixas etárias, entre adultos e pequenos, em tempos e em ritmos remansos, ensinares-e-aprenderes coletivos, desaguam para possíveis usos nas experiências escolares da escola formal, a de uma educação da infância amazônica, própria e diferenciada.

\section{REFERÊNCIAS}

ANDRADE, S. S.; PACHECO, T. do S. C. Infâncias e crianças ribeirinhas da Amazônia marajoara: linguagens e práticas culturais. Revista @rquivo Brasileiro de Educação, Belo Horizonte, v. 4, n. 9, set. /dez. 2016. p. 104-116.

BASTOS, A. P. V. et al. Economia e sociedade na região do Tocantins, Pará. UFPA, NAEA. Belém, n. 259, 2010. p. 1-32. 
BRANDÃO, C. R. Olhar o mundo e ver a criança: Ideias e imagens sobre ciclos de vida e círculo de cultura. Crítica educativa (Sorocaba/SP), Vol.1, n.1, jan./jun. 2015. p.108-132.

BRANDÃO, C. R. Reflexões sobre como fazer trabalho de campo. Rev. Sociedade e Cultura, v. 10, n. 1, jan. /jun. 2007. p. 11-27.

BRANDÃO, C. R. Aqui é onde eu moro, aqui nós vivemos: escritos para conhecer, pensar e praticar o município educador sustentável. $2^{a}$ ed. - Brasília: MMA, Programa Nacional de Educação Ambiental, 2005.

CASTRO, E. Terras de preto entre rios e igarapés. In: CASTRO, E. Belém de Águas e Ilhas. Belém: CEJUPA, 2006.

FONSECA, C. Quando cada caso NÃO é um caso: pesquisa etnográfica e educação. Revista Brasileira de Educação, Rio de Janeiro, ANPEd, n. 10, jan./abr., 1999. p. 58-78.

GUSMÃO, N. M. M. Olhar viajante: Antropologia, criança e aprendizagem. Revista Pro-Posições, Campinas, v. 23, n. 2 (68), p. 161-178, maio/ago. 2012.

INSTITUTO BRASILEIRO DE GEOGRAFIA E ESTATÍSTICA (IBGE). Documentação do Censo 2020. Rio de Janeiro: IBGE, 2020.

LIONETTI, L. (Org.). La historia de las infancias en América Latina. Tandil: Universidad Nacional del Centro de la Provincia de Buenos Aires, 2018.

MARTINS, J. de S. (Org.). Regimar e seus amigos: a criança na luta pela terra e pela vida. In: MARTINS, J. de S. Fronteira: a degradação do Outro nos confins do humano. $2^{a}$ ed. São Paulo: Contexto, 2014.

POJO, E. C. T. Gapuiar de saberes e de processos educativos e identitários na comunidade do rio Baixo Itacuruçá, Abaetetuba - PA. 243 p. Tese (Doutorado) Universidade Estadual de Campinas, Instituto de Filosofia e Ciências Humanas. Campinas - SP, 2017.

ROSEMBERG, F. Crianças e adolescentes na sociedade brasileira e a Constituição de 1988. In: OLIVEN, R. G.; RIDENTI, M.; BRANDÃO, G. M. (Org.). A Constituição de 1988 na vida brasileira. São Paulo: Hucitec, 2008.

TIRIBA, L. Educação infantil como direito e alegria. Laplage em Revista (Sorocaba), vol.3, n.1, jan./ abr. 2017, p. 72-86.

UNICEF. Pobreza na Infância e na Adolescência. 2018. Disponível em: https://www.unicef.org. Acesso em: 08 set. 2020.

Recebido em: 12 de setembro de 2021 . Aprovado em: 20 de dezembro de 2021.

Publicado em: 07 de janeiro de 2022. 